\title{
VIDA Y COSTUMBRES DE LOS CLERIGOS EN LA SOCIEDAD AMERICANA A TRAVES DE LOS SINODOS DE LOS SIGLOS XVII Y XVIII
}

\author{
por \\ ENRIQUE BANDE RODRIGUEZ
}

\section{INTRODUCCION}

La palabra Sínodo entraña la idea de Consejo, Asamblea religiosa o reunión de Obispos y clérigos que rigen las iglesias locales. Muchas veces los términos Sínodo y Concilio se emplean indistintamente. Son los Sínodos un código del Derecho Diocesano y uno de los saludables remedios para la buena gobernación del clero cristiano ${ }^{1}$.

Entre sus componentes ocupa el primer lugar el Obispo, que es el presidente, le siguen los párrocos, abades, vicarios y capellanes.

La finalidad de los Sínodos es hacer llegar a todos los fieles las normas del derecho común o de los Códigos y aquellas que emanan del mismo Sínodo, aunque muchas de estas serán llevadas a la práctica mediante las $1-8$

' RUIZ DE VALDIVIESO, P: Sinodales del Obispado de Orense. Madrid 1620, pág.

"CUADERNOS DE ESTUDIOS GALLEGOS", Tomo XL, Fascículo 105, Santiago 1992. 
visitas pastorales. Tratan de conservar ileso o íntegro el sagrado depósito de la Unidad de la Fe y Santidad de la Moral, para estirpar errores, reformar costumbres, arreglar y uniformar la disciplina acomodándola a la variedad y circunstancias de los tiempos ${ }^{2}$. Pretenden afirmar la caridad, sostener el buen régimen y cuidar que los vicios no engendren raíz. También quieren ejercer un control sobre la formación y disciplina del clero y demás religiosos, su vida y costumbres, su ejercicio pastoral no introduciendo innovaciones sino reflejando el tradicionalismo, la meticulosidad y el rigor tridentinos.

Contienen además innumerables prohibiciones que se refieren a veces a temas mínimos y pintorescos tales como la indumentaria y uso del tabaco. Hacen hincapié en las costumbres de los fieles, las fiestas, las diversiones, el culto en parroquias, capillas y ermitas, los ritos religiosos y supersticiosos, los derechos funerarios, el comportamiento en la iglesia tanto de clérigos como de laicos, y en ellos se describe la sociedad, la picaresca, las creencias, el trabajo, el matrimonio, etc., pretendiendo corregir abusos y aberraciones humanas de todo tipo, resaltando los aspectos negativos donde radica su mérito y también su limitación.

De los Sínodos Americanos se desprende una preocupación por el adoctrinamiento de los Indios, pues se repiten normas referentes a la Doctrina Cristiana y a la catequesis que a ellos hay que destinarles, y es aqui donde radica la gran novedad de los Sínodos americanos, dado que implican una preocupación e interés en el trato que se había de dar a los indígenas y el problema misional. Comienzan señalando que todo fiel cristiano está obligado a creer y saber todo lo relativo a diezmos, primicias, costumbres y tradiciones religiosas.

En la evolución de los Sínodos Americanos que comienzan con el Concilio de Trento podemos distinguir dos etapas, la primera se sitúa entre 1550 y 1630 coincidiendo con la Edad de Oro celebrándose en este tiempo más de medio centenar de sínodos. La segunda etapa se inicia a partir de 1638. A través de estas constituciones sinodales se transparentan las fiestas, las costumbres litúrgicas y las tradiciones religiosas del pueblo americano y como el clero fomentaba el catolicismo popular. También en los sínodos se nos refleja la costumbre de representar comedias y autos sacramentales

${ }^{2}$ BEDOYA, J. M.: Constituciones sinodales del Obispado de Orense. Imprenta de Don Juan María Pazos. Orense 1843. Pág. 3-10.

"CUADERNOS DE ESTUDIOS GALLEGOS", Tomo XL, Fascículo 105, Santiago 1992. 
dentro y fuera de las iglesias con finalidad catequética y como medio eficaz para desterrar el analfabetismo que en aquella época imperaba en la sociedad colonial.

Hallamos por lo tanto en los Sínodos, aspectos sociológicos, económicos, demográficos, históricos, litúrgicos, folclóricos y culturales donde el investigador puede encontrar una radiografía de la sociedad y la iglesia de la época colonial.

No sabemos con certeza si llegaron a ponerse en práctica o quedaron en mera letra pequeña, esto sólo lo podemos averiguar consultando los libros de visitas y estudiando las instrucciones dadas a los visitadores, quienes darán cuenta una vez cada tres años del estado en que se encuentra la parroquia ${ }^{3}$. Por tanto no sabemos si las constituciones fueron incumplidas o aplicadas a la realidad y necesidades pastorales del momento. Siguiendo un esquema ordenado trataremos de la vida y costumbres clericales, vida y costumbres de los fieles, de la mujer y de las fiestas prohibidas.

\section{VIDA Y COSTUMBRES DE LOS CLERIGOS}

Los Sínodos americanos le dedican mucha atención a la vida y costumbres de los clérigos, quienes por estar colocados en más alto lugar que los legos y llamados a la suerte del Señor deben tener mayor perfección de costumbre, seriedad, modestia, circunspección y su vida ha de ser espejo para que los laicos se muevan a imitarlos y para que compongan sus costumbres ${ }^{4}$.

La dignidad sacerdotal exige que la persona que haya de ser dedicada al culto y promovida al sacerdocio ha de presentar la fe de bautismo, han de dar información de su buena vida y costumbres, ha de ser hijo legítimo de padres cristianos viejos, limpios de toda mala raza de judíos, herejes, moros y reconvertidos a nuestra santa fe católica y no menores de 14 años. No deben ser ascendidos a las sagradas órdenes los hijos de los que fueren castigados por el Santo Oficio, ni los negros, ni mulatos, ni mestizos por la indecencia que resulta al estado clerical ${ }^{5}$. Es tan excelso el estado clerical y la dignidad

${ }^{3}$ SANTIAGO-OTERO, H.; GARCIA Y GARCIA, A.: Sínodos Americanos. Sínodo de San Juan de Puerto Rico de 1645. Ed: CSIC. Madrid-Salamanca. 1986. Pág. 141.

${ }^{4}$ Sínodo de Concepción de Chile. Año 1747. Const. I, Capítulo 4.

${ }^{5}$ Sínodo de Concepción de Chile. Año 1747. Const. XII, Capítulo 3.

"CUADERNOS DE ESTUDIOS GALLEGOS", Tomo XL, Fascículo 105, Santiago 1992. 
sacerdotal que exige que los sacerdotes vivan con decencia interior y exterior como pide su estado y su dignidad. Los Sínodos les mandan que en lo interior y lo exterior vivan de acuerdo con su estado y dignidad desterrando de sus vidas las tinieblas de los vicios. Vivan honestamente, cumplan las obligaciones de su estado, las cuales ha de ejecutar con toda exactitud y vigilancia ${ }^{6}$.

Siendo los clérigos llamados a la suerte del Señor es preciso que no sólo cultiven interiormente la virtud sino también que ese cuidado se conozca exteriormente por la modestia del vestido y por la compostura de sus acciones para que edifiquen con su ejemplo a los fieles. Han de tener siempre en su memoria la sagrada dignidad, han de estar apartados de la manera de vivir temporal, han de tener siempre en su memoria presente la sagrada dignidad pues son la luz del mundo y con su modo de vida han de ayudar a desterrar las tinieblas y los vicios, siendo ejemplo para la república cristiana. Deben llevar una vida ejemplar no siendo escandalosos; sino modestos, recogidos, quietos y pacíficos sin pecado público, no revoltosos ni pleiteantes, alejados del trato familiar con personas de mala vida y costumbres; han de ser ejemplares en sus conversaciones y acciones desterrando de sus vidas las deshonestidades ${ }^{7}$.

\subsection{Compostura clerical y vestido de los clérigos}

Los sínodos americanos le dedican mucha atención a la vida y costumbres de los clérigos.

Los sínodos les exigen que vivan con honestidad y compostura, que no traten familiarmente con mujeres, que residan en sus casas, que no se dediquen a juegos prohibidos, ni asistan a fiestas, bailes, rondas ni comedias, no lleven armas, ni se dediquen a ocupaciones prohibidas ni vistan máscaras.

En su hábito han de mostrar virtud y recogimiento interior pues los concilios llaman menospreciadores de su oficio a los que en el hábito y adorno corporal no muestren la virtud y limpieza de su alma. El Concilio de Trento dice que aunque el hábito no hace al monje, el clérigo que en el no muestra la honestidad de sus buenas costumbres anda con los piés puestos en diferentes partes: el uno en lo sagrado y espiritual y el otro en lo temporal y profano. Los sínodos amonestan una y otra vez a los clérigos, para que no traigan hábitos talares de colores profanos, entienden los sínodos por colores

\footnotetext{
${ }^{6}$ Sínodo de Santiago de Chile. Año 1686. Libro III. Const. III, pág. 64.

${ }^{7}$ Sínodo de Puerto Rico. Año 1645. Const. LXXXIII.

"CUADERNOS DE ESTUDIOS GALLEGOS", Tomo XL, Fascículo 105, Santiago 1992.
} 
profanos los que no fueren negro, pardo, leonado, oscuro cabellado y morado.

El traje clerical ha de ser de color honesto, las sotanas no sean de damasco, raso liso ni charneleta a lo más de tafetán doble negro, no usen los modos de vestir que intenta la profanidad ni vistan casacas de corte militar, colores vivos, ni franjas, ni hevillas de oro y plata. Les repite que no traigan medias de colores ni bordaduras, ni franjas o pasamanos de oro o plata, no traigan zapatos picados con talones altos ni capotes, ni anden por las calles de día en ropa de noche, esto es, en calzas o jubón. No anden sin corona abierta, con melenas, coletas, bigotes, con sombrero, anillos o sortijas. Les impone a quienes tal hicieren seis días de cárcel la primera vez ${ }^{8}$. El sínodo les recuerda una y otra vez la honestidad en el traje y manda que no solo las sotanas y manteos sean de color negro, pardo, oscuro y no de algún otro paño bajo pena de cuatro pesos; manda que guarden recogimiento y que de noche no salgan y si tuvieran necesidad de salir serán vestidos decentemente, con luz, sin disfraces, sin armas y sin ser en traje militar ${ }^{9}$. Traigan de manifiesto la coronilla clerical y no dejen guedejas sino se corten el pelo sobre peine sin traer bigote erizado o muy crecido ni pelo de modo que pase del cuello y no usen peluquín o coleta postiza ${ }^{10}$.

Cuando por la ciudad anden en mula, se les prohibe llevar ponchos o mantas, porque desdice de la seriedad eclesiástica. Los clérigos siempre deberán llevar el pelo cortado sobre peine, sin usar coletas.

\subsection{Trato con mujeres y barraganas}

Los sínodos les exigen que vivan con honestidad, con compostura, que no traten familiarmente con mujeres. Que no tengan en sus casas ni en otras partes mujeres sospechosas (entiende el sínodo por tales aquellas que pueden inducir a desonestidad o aquella con la que fue infamado, la que no fuere madre, hermana o prima hermana que esté dentro del segundo grado de consanguinidad siendo ella de buenas formas). Pueden tener madres, hermanas y primas hermanas. Los sínodos les ponen como pena a los que les tengan que las echen de sus casas antes de ocho días. El clérigo que tenga mujer en su compañía y de ella hubiere murmuración, fama o escándalo sea castigado

\footnotetext{
${ }^{8}$ Sínodo de S. Juan de P. R. Año 1645. Const. I.

${ }^{9}$ Sínodo de Concepción de Chile. Año 1747. Const. III, Cap. 4, Tít. 4.

${ }^{10}$ Sínodo de Santiago de Cuba. Año 1645. Const. XVII. 
como manda el derecho y le eche de su casa dentro de ocho días. Les imponen también la obligación de cumplir el mandato bajo pena de excomunición mayor y diez ducados de multa ${ }^{11}$. Si pasados cuatro días no lo hiciere ha de ser tenido por sospechoso.

Les mandan también que no sean padrinos de casamientos, ni ejerzan la medicina, la cirujía, ni oficios mecánicos propios de la gente sencilla.

Les manda evitar el servicio de mujeres mozas españolas o indias. Podrán valerse de criados varones o de alguna mujer anciana de la que no haya sospecha, que no tengan hijas con quienes pueda peligrar el buen crédito del párroco. Les recuerda a los clérigos que no ofendan a Dios nuestro Señor ni a su hábito para no ser menospreciados de los seglares. Está prohibido que los clérigos acompañen a mujeres a pié o a caballo por el grave absurdo que resulta de que los eclesiásticos destinados al altísimo ministerio del altar se ocupen en ejercicio tan poco decoroso ${ }^{12}$. El sínodo ordena a los clérigos eviten en sus casas el servicio y consorcio de mujeres mozas y que eviten las sospechas pues muchas veces aunque no haya culpa siempre se desedifica a los laicos a quienes deben dar ejemplo en todas sus acciones. El visitador en sus visitas pondrá especial cuidado en estas averiguaciones ${ }^{13}$.

El pecado carnal debía de ser muy frecuente igual que el amancebamiento pues los sínodos mandan al visitador que cuando haga información y hallase delitos de flaqueza con mujeres casadas no nombre a las dichas mujeres.

Solo le manda que diga que están amancebados con mujer que por su honestidad no se nombra y no siendo negocio público traten el asunto con gran secreto para que no aumente la infamia ni se haga mayor daño. En cualquier otra flaqueza que no sea pública se procederá asimismo para que se conserve la honra de las personas difamadas ${ }^{14}$. Los castigos serán los siguientes:

- Ser privados de la tercera parte de sus prevendas.

- Ser suspensos de sus beneficios.

- Quedar privados de todos sus beneficios, y si no los tuvieran ser castigados en proporción de su contumacia, con pena de cárcel, suspensión de orden e inhabilidad para obtener beneficios.

\footnotetext{
"Sínodo de Concepción de Chile. Año 1747. Const. VI. Cap. 4.

${ }^{12}$ Sínodo de Concepción de Chile. Año 1747. Const. VII. Cap. 4.

${ }^{13}$ Sínodo de S. Juan de Puerto Rico. Año 1645. Const. CLXXXIV.

${ }^{14}$ Sínodo de S. Juan de Puerto Rico. Año 1645. Const. IV.
} 


\subsection{Oficios prohibidos a los clérigos}

Los sínodos le imponen que no ejerzan la abogacía, la medicina, la cirugía, ni oficios mecánicos propios de las gentes del campo. Ningún clérigo se ejercite en oficios indecentes a su estado trabajando en cultivar los campos, aderezar casas y otras cosas semejantes. Los sínodos les imponen a los contraventores la pena de doce pesos por cada vez. Como puede observar el lector hallamos aqui reminiscencias de la deshonra legal del trabajo en la España Imperial cuando se pensaba que el trabajo no era ocupación de nobles y cuando el ideal de una gran parte de la sociedad era vivir a lo noble ${ }^{15}$.

Los clérigos no ejercerán oficios y negocios seculares, no traten ni contraten ni ejerzan oficios de mayoralías, de mayordomos de personas seculares ni eclesiásticas, no ejerzan oficios mecánicos, ni sean tratantes ni inclinados a logros o usuras.

Estando prohibido todo género de mercadurías y contrataciones mandamos bajo pena de excomunión mayor latae gententiae que ningún clérigo compre, venda ni arriende tierras, rentas o diezmos, ni conmute, ni tenga caballos ni mulo de alquiler en que anden los indios. El sínodo le permite que para su sustento pueda criar ganados ${ }^{16}$. No pueden los clérigos vender los restos que no fueren patrimoniales o de renta eclesiástica, ni puedan comprar cosas o venderlas en la misma especie o mudarlas en otra para ganar dinero ${ }^{17}$. La principal y más funesta indecencia de la negociación es la venta, permuta y otros géneros de trato con indios o colonos domésticos cambiando algunas mercancías o ganados por los ponchos o mantas y más si se excede en la introducción de armas y caballos y en mantener crías de todo género y cultivar viñas y otras plantas y semillas con el fin de venderlas ${ }^{18}$.

Conviene mucho que los eclesiásticos eviten comunicaciones con seculares. Esto les impone el sínodo bajo pena de doce pesos y quince días de reclusión en la iglesia la primera vez, por la segunda vez doblado, y por la tercera quedarán sin pensión.

\subsection{Juegos y actos festivos prohibidos a los clérigos}

A los clérigos también les está prohibido tener en sus casas tablajes de juegos, naipes, pelota, dados, ni farola de juego de truco ni argolla ni otros

\footnotetext{
${ }^{15}$ Sínodo de S. Juan de Puerto Rico. Año 1645. Const. IV.

${ }^{16}$ Sínodo de S. Juan de Puerto Rico. Año 1645. Const. LXII.

${ }^{17}$ Sínodo de Concepción de Chile. Año 1747. Const. IX. Capt. 4.

${ }^{18}$ Sínodo de Santiago de Cuba. Año 1747. Const. III. Pág. 64.
} 
juegos, ni admita en su casa a los seglares para los dichos juegos haciendo de ella un lugar de entretenimiento público pues de ello se sigue perder el tiempo y es ocasión de murmuraciones, perjurios y blasfemias. No entren en casas públicas de juegos y mesas aunque solo sea para ver jugar. Ni jueguen dinero. El sínodo solo les permite hacerlo hasta la cantidad de dos o tres pesos siendo juegos prohibidos ${ }^{19}$. Los sínodos mandan también que ningún clérigo de orden sacro represente o entre en comedias, autos, fiestas, danzas, músicas, regocijos y mascaradas, ni se vista de mamarracho, aunque las tales fiestas sean el día de Corpus Cristi o en las solemnidades de la igle-sia. Les recuerda que es gran indecencia que anden los clérigos de noche rondando y haciendo desordenes. Condenan y mandan que ninguno dé músicas por las calles no ronde ni toque instrumentos musicales. A los que estas cosas hicieren les pone cien maravedíes de pena la primera vez ${ }^{20}$.

Les manda que lo cumplan bajo pena de excomunión mayor, de un mes de cárcel y de seis pesos de multa la primera vez ${ }^{21}$. También les prohiben andar en cuadrillas, o bandas, danzas, festines y en todo juego de bulla o de placer.

\subsection{Prohibición de llevar armas los clérigos}

Los sínodos les prohiben a los clérigos traer armas ofensivas y defensivas, ni entrar con ellas en las iglesias Entienden los sínodos por armas las que sean de hierro, acero, mallas, pistolas, pistoleras, y otras semejantes. Los que las llevaren serán castigados conforme a la culpa. Les permiten que cuando vayan al campo puedan llevar espadas pero no las traigan al pueblo dejándolas en las posadas. Si las trajeren en el pueblo o fueren con ellas les castigue el sínodo con la pérdida de dicha espada y seis días de cárcel ${ }^{22}$.

\subsection{Residencia Clerical}

Al clérigo que tenga beneficio clerical curado los sínodos le imponen la obligación de residencia bajo pena de pecado mortal y le mandan que residan en casa propia cerca de la iglesia y si no la tuvieren propia resida en parte conocida donde pueda ser hallado con facilidad.

\footnotetext{
${ }^{19}$ Sínodo de San Juan de Puerto Rico. Año 1654. Const. XVI.

${ }^{20}$ Sínodo de S. Juan de Puerto Rico. Año 1645. Const. LVII.

${ }^{21}$ Sínodo de S. Juan de Puerto Rico. Año 1645. Const. LXII.

${ }^{22}$ Sínodo de Santiago de Chile. Año 1688 y 1763. Tít. IX. Const. VIII.
} 
Para salir de casa aunque sea por las tardes y para hacer algún ejercicio usen siempre gabán largo que pueda llamarse talar y del color expresado antes, de cuello clerical que esté de manifiesto y ninguno salga solo con capote o chupa o casaqueta corta dentro de la ciudad bajo pena de cuatro pesos ${ }^{23}$.

\subsection{El cuidado Pastoral}

Los sínodos americanos recojen también las normas referentes a la práctica pastoral en las diocesis y las referentes a la administración de los sacramentos, las visitas a los enfermos, al precepto pascual, a los funerales, a las obras pías, al petitorio, al cuidado de las iglesias, a la vida matrimonial, a las cofradías y procesiones, a las ermitas y capillas, al cuidado pastoral del crisma y del oleo a los ritos supersticiosos y a la erección de ermitas y capillas.

Los curas párrocos administren a sus fieles los santos sacramentos y les conozcan como ovejas que están a su cuidado. No se desentiendan de sus beneficios curados y curatos por más de dos meses bajo pena de pérdida de los frutos y esto con justa causa y con licencia del obispo in scriptis y manda que todos personalmente administren los santos sacramentos, pues mal pueden curar las enfermedades y la lepra de las almas de sus ovejas si no las ven por su persona para aplicarles el remedio ${ }^{24}$. El sínodo se queja de que se ha introducido un abuso por poco respeto a la iglesia, por pereza y flojedad de los contrayentes al celebrar el sacramento del matrimonio en casas particulares sin justa causa y de administrar el de la penitencia de igual forma y aún de noche de lo que se siguen muchos años. Manda que no confiesen ninguna persona en casa particular no estando enferma, ni de noche en la iglesia ni en parte oculta por mala nota y por el escándalo que de ello se pudiera seguir y que para administrarlas estén sentados y con bonetes ${ }^{25}$. Además de la obligación que tienen los curas de administrar todos los sacramentos a sus feligreses enfermos les exorta a que asistan con toda caridad a los moribundos cuando están en extremo peligro de la vida ayudándoles y encomendándoles en trance tan difícil y les recuerda que no cesen en esta obra

\footnotetext{
${ }^{23}$ Sínodo de Santiago de Chile. Año 1747. Cap. 4. Tít. 4.

${ }^{24}$ Sínodo de Santiago de Chile. Año 1681. Const. V, Libro I, Tít. 7.

${ }^{25}$ Sínodo de Santiago de Cuba. Año 1681. Const. XIII, Libro 3, Título 6.
} 
heroica y de caridad ${ }^{26}$. Manda también el sínodo que en todas las iglesias, catedrales y parroquias del obispado se den unos golpes de campana para avisar que alguno está en peligro de muerte, con distinción de varón o hembra para que los fieles encomienden a Dios al moribundo y le ayuden con sus familiares a pasar el trance tan apretado de la muerte ${ }^{27}$.

Los obispos mandan a los curas no consientan hacer duelos de llantos por los difuntos como suelen hacer los negros por los suyos y por sus amos difundos dando grandes alaridos mesándose los cabellos y haciendo otras demostraciones que no son de cristianos causando al enterrar los difuntos mucha confusión. Esto dice el sínodo que está prohibido por las leyes del reino. A los que hicieren tales llantos en la iglesia o en casas de los difuntos le echen de la iglesia y del acompañamiento del entierro y si fuese necesario les quiten los lutos y los vendan para misas por el difunto.

Visiten y asistan frecuente y cristianamente a los indios enfermos en el artículo de la muerte, enseñándoles a morir como verdaderos cristianos ${ }^{28}$. Les recuerda que cada mes visiten a los indios enfermos para consolarles con los auxilios espirituales y corporales ${ }^{29}$. El visitador tendrá cuidado de vigilar como se cumple este mandato ${ }^{30}$.

Entre los indios hay una costumbre perniciosa de celebrar convites donde se entierra un miembro de la comunidad de lo que se siguen no pequeños daños temporales y espirituales. Para evitarlos manda el sínodo a los párrocos no permitan semejantes convites y enseñen que sus fiestas cuando las celebren sean conforme a las costumbres de los fieles cristianos ${ }^{31}$. Les mandan también que los confesionarios destinados para confesiones de mujeres sean con rejas para oirlas por ellas y si se confiesan de noche por el concurso de gente manda el sínodo que pongan luces en los altares de las iglesias ${ }^{32}$.

Visto el grave inconveniente que se sigue del empleo de las limosnas que se piden para las cofradías, ermitas y hospitales sobre todo cuando se pide por arrendamientos o salarios manda que se gasten en aquello para lo que las

\footnotetext{
${ }^{26}$ Sínodo de Santiago de Chile. Año 1747. Const. XXVII, Libro 1, Tít. 7.

${ }^{27}$ Sínodo de Santiago de Cuba. Año 1681. Const. XII, Libro 3, Tít. 6.

${ }^{28}$ Sínodo de San Juan de Puerto Rico. Año 1645. Const. XXIII.

${ }^{29}$ Sínodo de Concepción de Chile. Año 1747. Const. VI, Cap. 5.

${ }^{30}$ Sínodo de San Juan de Puerto Rico. Año 1645. Const. XIV.

${ }^{31}$ Sínido de San Juan de Puerto Rico. Año 1645. Const. XII.

${ }^{32}$ Sínodo de S. Juan de Puerto Rico. Año 1645. Const. XII.
} 
dan los fieles y prohibe que se pidan dichas limosnas por arrendamiento o salarios y se haga por cofrades y demás personas a quienes por su oficio les pertenece y manda que las limosnas se empleen en aquello para lo que los fieles las dan y no consienten que se pidan algunas limosnas particulares con insignias ni que para recibir limosnas se publique indulgencias. Es muy dañoso a las iglesias el uso de cuestores y personas que publiquen indulgencias porque engañan al pueblo ignorante. Le manda a los vicarios no consientan que se publiquen sin licencia del obispo ni permite que pidan limosnas ni vistan hábitos de santeros ${ }^{33}$.

Les mandan los sínodos que en las iglesias y capillas particulares las pilas bautismales las tengan con una reja cerrada con llave pues así lo exige para el sacramento del agua bautismal ${ }^{34}$. También les ordenan a los abades que cada año por persona de satisfacción o por un clérigo vaya al lugar donde se hallan consagrados los santos óleos y lleven una cajita con su llave y una vez recogidos los tengan con la decencia debida por ser el crisma y los óleos sagrados materia de algunos sacramentos y necesarios para la consagración de aras y campanas. Se requiere que los tengan en sus iglesias con la decencia debida y con la debida veneración en alguna alacena de la sacristia y donde no la hubiere mandan los sínodos que se haga bajo pena de cinco pesos ${ }^{35}$. También les mandan los sínodos que no celebren en altares portátiles ni en el campo ni en casas particulares bajo ningún pretexto. Dado que el lugar indicado para tener los nacimientos es el templo de Dios y dado que de ponerse en las casas particulares resultan muchas indecencias y poca reverencia a las imágenes sagradas manda el sínodo que no se hagan altares en casas particulares ni nacimientos en que intervengan, misivas, bailes, concursos de gente y otras indecencias bajo pena de excomunión mayor y de 10 ducados.

No se prohiben los altares y nacimientos en que se ponga un determinado número de velas en casas de personas virtuosas y recogidas con la decencia debida, allí se ha de congregar la familia y rezar el rosario y la doctrina cristiana ${ }^{36}$.

Los días más sagrados de la Navidad del Señor, de la Santa Cruz, de San Juan Bautista y del patrono con pretexto de pía devoción se acostumbra

\footnotetext{
${ }^{33}$ Sínodo de S. Juan de Puerto Rico. Año 1645. Const. CLX.

${ }^{34}$ Sínodo de S. Juan de Puerto Rico. Año 1645. Const. XLIV.

${ }^{35}$ Sínodo de Santiago de Chile. Año 1681. Const. III.

${ }^{36}$ Sínodo de Santiago de Chile. Año 1681. Const. VII, Libro I, Tít. 2.
} 
hacer altares en casas particulares que se profanan con el concurso de hombres y mujeres y por ello el sínodo manda no se hagan dichos altares en las casas los días referidos ni en otros días ${ }^{37}$. No se prohiben los que se hagan en algunas piezas secretas sin permitir el concurso de ambos sexos para que los de la familia hagan rogación a Dios ${ }^{38}$. Les dicen además que en las imágenes adoramos a Cristo y reverenciamos los santos de quien son semejanza pero algunas veces están mal pintadas estragadas, y no se les tiene el respeto que les es debido y por ello los sínodos mandan que se pinten para que no causen indecencia ${ }^{39}$. También les mandan que les adviertan a los testamenteros de los difuntos que las mandas pías se han de comenzar a cumplir inmediatamente sin esperar a que pase un año ${ }^{40}$. Les mandan que no edifiquen ermitas o capillas en ingenios, hatos o corrales ni en otra parte sin licencia de Su Majestad ${ }^{41}$. Entrelas obligaciones pastorales de los curas está por derecho o costumbres la de avisar al pueblo de los días festivos, de ayuno, y rogaciones. El sínodo manda que todos los domingos del año en las misas mayores al tiempo del ofertorio anuncien al pueblo los días que hay obligación de ayunar y los que son de rogaciones de la iglesia y otras que se hacen por la salud del pueblo. Esto se lo imponen los sínodos bajo pena de un ducado ${ }^{42}$.

Les mandan también a los párrocos tengan un libro en que asienten los matrimonios españoles, otro en que se pongan los matrimonios de negros, mulatos, indios y esclavos; otro para que asienten los nombres de los negros, mulatos, indios, esclavos y libres ${ }^{43}$.

\subsection{Enseñanza de la doctrina cristiana}

Una de las obligaciones de los ministros evangélicos es enseñar la doctrina cristiana a sus feligreses y predicarles la palabra del evangelio. Mandamos a los doctrineros junten a los indios menores de 12 años y a las indias de 9 todos los días dos horas por la mañana y dos por la tarde y les enseñen la doctrina cristiana los domingos y fiestas de guardar.

\footnotetext{
${ }^{37}$ Sínodo de Concepción de Chile. Año 1747. Const. XIV, Cap. 15.

${ }^{38}$ Sínodo de Santiago de Chile. Año 1668 y 1763. Const. VII, Tít. 12.

${ }^{39}$ Sínodo de San Juan de Puerto Rico. Año 1645. Const. CVII.

${ }^{40}$ Sínodo de S. Juan de Puerto Rico. Año 1645. Const. X.

${ }^{41}$ Sínodo de Santiago de Chile. Año 1681. Const. I, Lib. III, Tít. 9.

${ }^{42}$ Sínodo de Santiago de Cuba. Año 1681. Const. XII, Lib. I, Tít. 1.

${ }^{43}$ Sínodo de Santiago de Chile. Año 1681. Const. IV, Lib. 1, Tít. 7.
} 
Les enseñarán la oración de Pater Noster, el ave María, el símbolo de los apóstoles, los artículos de la fe, mandamientos de la ley de Dios y de la iglesia, y principales misterios de nuestra santa $\mathrm{fe}^{44}$. A quienes no las supieren se les dilate el contraer matrimonio.

En los domingos de adviento y cuaresma les expliquen el santo evangelio y a los muchachos se les enseñe todos los días como lo hacen. Les rogamos y encargamos si les pudieren enseñar en la lengua castellana lo hagan por el mucho provecho que de ello resulta. Los doctrineros tengan también pericia en la lengua de los indios que han de administrar y de no ser así sean removidos, pues hay quienes no entienden el castellano ${ }^{45}$. El sínodo exige que las personas que han de enseñar la doctrina cristiana sean virtuosas, de buena vida y costumbres y que el juez ordinario les examine de la doctrina cristiana ${ }^{46}$. Las encomiendas de indios fueron fundadas no tanto para beneficio y utilidad de los encomenderos cuanto para que como padres pedagogos y pastores los instruyan en las cosas de la fe y en la política cristiana defendiéndoles y amparándoles de quienes les intenten agraviar.Lo contrario es causa para privar de encomienda. Los encomenderos acostumbren a sus indios a rezar la doctrina cristiana todos los días a la mañana antes de salir al trabajo. En todas las estancias de sus feligresías donde hubiere copia de indios antes de ponerse a la faena de la mañana concurran a la iglesia o lugar decente delante de una imagen y recen por medio de un fiel instruido el catecismo y oraciones. A los que lo impidan se les multará. Ningún encomendero de indios o personas a quienes sirvieren impidan a los indios el matrimonio que quisieren contraer ${ }^{47}$. Como muchos indios ignoran la doctrina cristiana y se hace difícil su enseñanza por falta de residencia fija el sínodo exige a los hacendados lleven a los indios que les adoctrinen y sino lo hacen podrá trasladar a los ignorantes al servicio de otros patronos ${ }^{48}$. El sínodo les manda y les pide afectuosamente a los amos, a los mayordomos y a los mayorales que en todos los corrales y haciendas antes de entrar a trabajar recen la doctrina cristiana siendo acompañada por persona mayor que la supiere. Para que los hijos de los indios facilmente puedan aprender la doctrina cristiana y el idioma español, manda el sínodo a los párrocos

\footnotetext{
${ }^{44}$ Sínodo de Concepción de Chile. Año 1647. Const. IV, Capt. 5.

${ }^{45}$ Sínodo de S. Juan de Puerto Rico. Año 1645. Const. IX.

${ }^{46}$ Sínodo de Santiago de Cuba. Año 1681. Const. IX, Lib. I, Tít. 1.

${ }^{47}$ Sínodo de Concepción de Chile. Año 1647. Const. VIII, Cap. 14.
} 
tengan escuelas públicas donde enseñen a leer y escribir a los hijos de los indios y que las indias de más de nueve años no acudan a la doctrina sino es acompañadas de sus madres y en día de fiesta.

Los maestros y maestras de niños enseñan la doctrina cristiana por el catecismo del P. Ripalda y no les den a leer sonetos profanos, ni novelas, ni libros de comedias y los maestros lleven a los indios a la iglesia para que les examinen y no sabiendo la doctrina les multen con un ducado ${ }^{49}$.

El sínodo manda que los maestros de escuela que no fueren sacerdotes o sacristanes no pongan escuelas ni enseñen en manera alguna sin que primero se haga información de su vida y costumbres y se les examine con licencia y aprobación del obispo, sea penado en 100 maravedíes quien no se atenga a la norma. Encarga a los maestros enseñen la doctrina cristiana a los niños y les hagan rezar según el catecișmo ${ }^{50}$. Les manda el sínodo a los visitadores que visiten a los dichos maestros y le informen de su suficiencia y proceder examinando a los maestros de su vida y costumbres y nos dé aviso del que hallaren digno de remedio.

Los padres y pastores espirituales, los dueños de los esclavos y los encomenderos de los indios están obligados a instruir a sus hijos y súbditos en todas las cosas necesarias para la salud de sus almas. Tengan particular cuidado y vigilancia que en sus iglesias enseñan la doctrina cristiana y estando impedidos permitimos que los sacristanes lo puedan hacer y lo hagan cada uno en su iglesia todos los domingos del año después del medio día y todos los de cuaresma después de la salve recitando y enseñando la doctrina cristiana y lo mismo han de hacer los capellanes de las estancias en sus ingenios todos los domingos acabada la misa o después del ofertorio cuando publique las fiestas y días de ayuno. Exortamos a los feligreses inviten a sus hijos esclavos y acomodados para que aprendan lo que es conveniente saber para salvarse. A los que enseñaren la doctrina cristiana concedemos por cada vez 40 días de indulgencia y para que todos la sepan le mandamos que los domingos se toque a las dos y los días de cuaresma cuando se toque a la salve que será una hora antes de anochecer.

El sínodo manda que los visitadores en las visitas examinen a los fieles y a los muchachos indios y esclavos para saber si están instruidos ${ }^{51}$.

\footnotetext{
${ }^{48}$ Sínodo de Santiago de Chile. Año 1688 y 1763. Const. XV. Tít. 19.

${ }^{49}$ Sínodo de Santiago de Cuba. Año 1681. Const. VIII, Lib. I, Tít. 1.

${ }^{50}$ Sínodo de San Juan de Puerto Rico. Año 1645. Const. XXX.
}

"CUADERNOS DE ESTUDIOS GALLEGOS", Tomo XL, Fascículo 105, Santiago 1992. 
Como uno de los principales ministerios de los curas es la predicación de la fe católica y de sus sagrados misterios y no menos de la palabra del santo concilio y su enseñanza de la doctrina cristiana todos los domingos y fiestas del año tocando la campana por lo menos en tiempo de cuaresma. Todos los domingos y días de fiesta en la misa platique al pueblo con pláticas proporcionadas a la capacidad del auditorio que siendo por lo común gente joven de pocos alcances los conceptos especulativos más le sirven de confusión que de provecho. Les adoctrinen en términos claros antes o después de la misa.

Habiendo reconocido mucha ignorancia en los misterios de la santa fe católica les enseñará la doctrina cristiana en el pórtico de la catedral las tardes de los domingos y fiestas del año convocándoles a toque de campana y manda a los amos de los cercados que les enseñen no habiendo causa precisa que los embarace y les multará con 34 azotes cuando culpablemente dejen de asistir.

Todos los domingos del año después de la ofrenda y por la tarde los curas y doctrineros, personas que dijeren la misa mayor del pueblo, aclaren el santo evangelio de aquel día y tengan cuidado por la tarde de ir instruyendo al pueblo en los artículos de la fe, en los mandamientos y preceptos de la iglesia, en lo que han de hacer para recibir los sacramentos, como se han de confesar, como deben guardarse de ofenderle y apartarse de los pecados mortales; enseñándoles que al entrar en la iglesia se signen, tomen agua bendita y hagan oración al Santísimo y se aparten de todas las supersticiones y errores ${ }^{52}$.

No es menor la obligación que tienen los padres de familia para con sus hijos menores que la de los padrinos de esclavos y por ello el sínodo manda a los padres de familia, a los dueños de los ingenios y de las haciendas y a todas las personas que tienen esclavos hacendados y a los tutores enseñen a sus súbditos y menores todas las noches la doctrina cristiana.

\footnotetext{
${ }^{51}$ Sínodo de S. Juan de Puerto Rico. Año 1645. Const. II.

${ }^{52}$ Sínodo de S. Juan de Puerto Rico. Año 1645. Const. II.

"CUADERNOS DE ESTUDIOS GALLEGOS", Tomo XL, Fascículo 105, Santiago 1992.
} 